\title{
Synthesis and Properties of Novel T-Type Polyurethanes Containing 2,5-Dioxynitrostilbenyl Group as a Nonlinear Optical Chromophore
}

\author{
Ju-Yeon Lee, "Won-Jung Lee, Eun-Ju Park, Han-Bae Bang, Bum Ku Rhee, \\ Changsoo Jung, ${ }^{\dagger}$ Seung Mook Lee, ${ }^{\dagger}$ and Jin Hyun Lee ${ }^{4}$ \\ Institute of Basic Sciences, Department of Chemistry, Inje lniversity, 607 Obang-dong, Kimhae 621-749, Korea \\ "Department of Phwics. Sogang University, Mapoku, Seoul 121-742. Korea \\ Received line 30,2003
}

Key Words : 2.5-Di-(2-hydroxyethoxy)-4-nitrostilbene, Nonlinear optical. T-Type polyurethane, $\Lambda F M$, SIIG coefficient

Functional materials of nonlinear optical (NLO) activities have been extensively studied over the past decade because of their potential applications in the lield of telecommunications, optical switching, ete. 'Among them. the NLO polymers are considered promising materials, mainly because they oller many advantages such as good processability to form optical devices. ${ }^{2}$ In the developments of NLO polymers for electrooptic device applications, stabilization of electrically induced dipole alignment is important considerations. Two approaches 10 minimize the randomization have been proposed. One is to use crosslinking method ${ }^{3-5}$ and the other is to use high $T_{y^{7}}$ polymers such as polyimides. ${ }^{6.7}$ Polyurethane matrix forms extensive hydrogen bond between urethane linkage and increases rigidity preventing the relaxation of induced dipoles. In this work we prepared new T-lype polyurethanes containing dioxynitrostilbenyl group as a NLO-chromophore. We selected 2,5-dioxynitrostilbenyl group as NLO-chromophore because it will have a large dipole moment and is rather easy to synthesize. Furthermore 2,5-dioxynitrostilbenyl group constitutes a novel T-1ype NLO polyurthanes, in which the NLO chromophores are parts of polymer backbones (Fig. 1B). These T-type NLO polyurethanes are not shown in the literature. Alier confirming the structure of the resulting polymers we investigated the properties such as $T_{y}$ and second harmonic generation (SI IG) activity $\left(d_{53}\right)$. We now report the results of the initial phase of the work.

2.5-Dihydroxy-4-nitrostilbene (1) was prepared by condensation of 4-nitrophenylacetic acid with 2,5-dihydroxybenzaldehyde according 10 a literature procedure. $\$$ 2.5-Di-
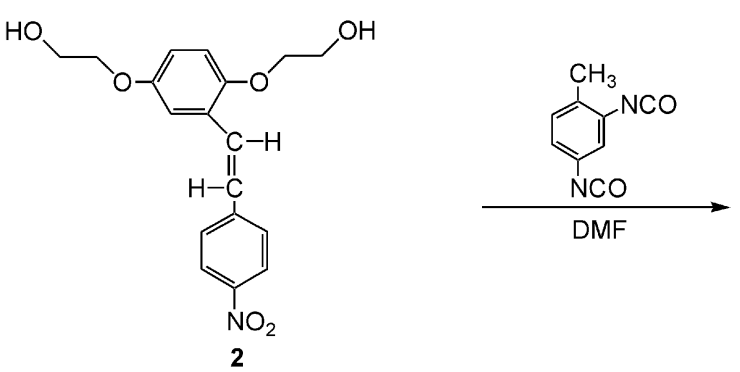

(A)

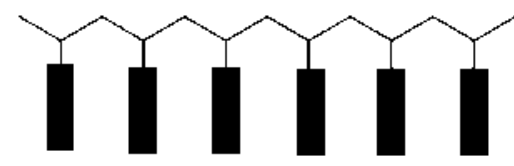

(B)

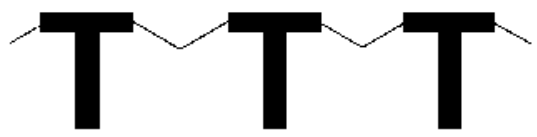

Figure 1. Side chatin NLO polymers $(\Lambda)$ and I-type $N L O$ polymers $(B)$.

(2-hydroxyethoxy)-4-nitrostilbene (2) was prepared by reaction of 2-iodoethanol with $\mathbf{1}$. Polymer 3 was prepared by polyaddition reaction between a diol 2 and 2,4-toluenedisocyanate (TDI) in a dry DMF solvent. Synthetic method of polymer 3 is summarized in Scheme 1. The chemical structures of the compounds were conlirmed by ' I J NMR. IR spectra and elemental analysis. The signal at 8.32-8.43 ppm of the 'II NMR spectra, assigned to the amide proton, indicates the formation of urethane linkage. The IR spectra of the same polymer samples also show a strong carbonyl peak near $1713 \mathrm{~cm}^{-1}$, indicating the presence of urethane bond. Two strong absorption bands due to the nitro group in the NLO-chromophore of the stilbene unit appeared near $1520 \mathrm{~cm}^{-1}$ and $1350 \mathrm{~cm}^{-1}$. These results are consistent with the proposed structures, indicating that the NLO-chromophore remained intact during the polymerization. We now have a novel T-lype polyurethane (3) and investigate its property.

The polymer 3 was soluble in common solvents such as acctone, DMF and DMSO, but were not soluble in methanol

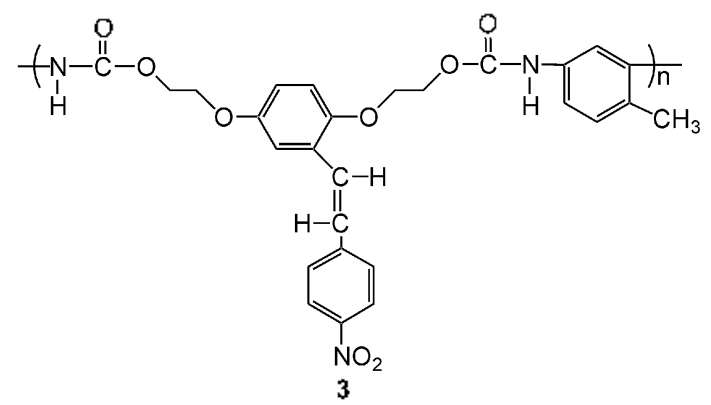

Scheme 1 
Table 1. Thenmal Properties of Polymer 3

\begin{tabular}{cccccc}
\hline \multirow{2}{*}{ Polymer } & $T_{\mathrm{g}},{ }^{\circ} \mathrm{C}$ & \multicolumn{3}{c}{ Degradation temp, ${ }^{\circ} \mathrm{C}$} & Residue at \\
\cline { 3 - 5 } & & $5 \%-\operatorname{loss}$ & $20 \%-\operatorname{loss}$ & $40 \%-\operatorname{loss}$ & $700{ }^{\circ} \mathrm{C}, \%$ \\
\hline 3 & 159 & 308 & 354 & 421 & 41.8 \\
\hline
\end{tabular}

and diethyl ether. The thermal behavior of the polymers were investigated by thenogravimetric analysis (TGA) and differential scanning calorimeter (DSC) to determine the thermal degradation pattern and glass transition temperature $\left(T_{g}\right)$. Polymer 3 showed a thermal stability up to $300^{\circ} \mathrm{C}$ from their TGA thermograms, as shown in Table 1. Glass transition temperature $\left(T_{g}\right)$ value of the polymer 3 measured by $\mathrm{DSC}$ was around $159^{\circ} \mathrm{C}$. To induce noncentrosymmetric polar order. the spin-coated polymer films were coronapoled $\left(170^{\circ} \mathrm{C} .6 \mathrm{kV}, 30 \mathrm{~min}\right)$. After the electric poling. the dipole monents of the NLO-chromophores were aligned and UV-Vis spectrum of polymer 3 exhibited a slight blue shift and a decrease in absorption due to birefringence. Fron the absorbance change, the order parameter of the poled film could be estimated, which is related to the poling efficiency. The estimated order parameter value was deduced to be 0.25 $\left(\Phi=1-A_{1} / A_{i}, A_{1}\right.$ and $A_{1}$ are the absorbances of the polymer film before and after poling). Domain structures of NLOchromophores for the poled thin-film saniples were obtained by using atomic force microscopy (AFM). Figure 2 shows AFM scans of the spin-coated film before and after poling for polymer 3. AFM inages show that the surface of the film sample is extremely flat and clean. However. this good quality film was dramatically changed after poling, resulting in numerous hills and valleys in the surface structure, which means that the NLO chromophores were aligned in the poling direction. The refractive index of the polymer sample was measured by the optical transmission technique. ${ }^{9}$ The transmittance of thin film includes the information of the thickness, refractive index and extinction coefficient of that. The NLO properties were studied by the SHG method. NLO properties of polymer 3 are summarized in Table 2. SHG measurements were performed at a fundamental wavelength of $1064 \mathrm{~nm}$ using a mode locked Nd-YAG laser. ${ }^{10.11}$ In order to determine the microscopic second-order susceptibility of the polymer. the angular SHG dependence was recorded. The SHG values were compared with those obtained from a Y-cut quartz plate. To calculate the $d_{31}$ and $d_{33}$ values. both $s-$ polarized and $p$-polarized IR laser were directed to the samples and recorded. The value of $d_{31}$ and $d_{33}$ for polymer 3 were $1.74 \times 10^{-9}$ esu and $5.36 \times 10^{-9}$ esu. respectively.

Since the second harmonic wavelength was at $532 \mathrm{~nm}$. which is not in the absorptive region of the resulting

Table 2. Nonlinear Optical Properties of Polvmer 3

\begin{tabular}{cccccc}
\hline Polymer & $\lambda_{\max }{ }^{a}$ & $d_{33^{b}}{ }^{b}$ & $d_{31}^{b}$ & $d_{3} / d_{31}$ \\
\hline 3 & 391 & $5.36 \times 10^{-9}$ & 0.25 & $1.74 \times 10^{-4}$ & 3.08 \\
\hline
\end{tabular}

"Polvmer film after corona poling. "SHG coefficients were derived from the analysis of measured Maker-fringes. ${ }^{17}{ }^{c}$ Order parameter $\Phi=1-A_{1}: A_{\|}$. $A_{0}$ and $A_{1}$ are the absorbances of the polymer film before and after corona poling. respectively.
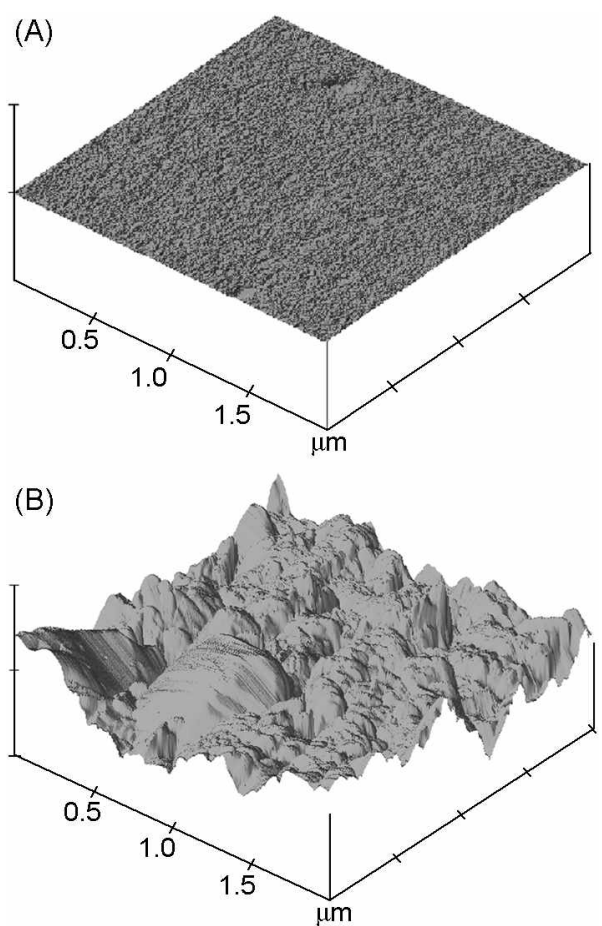

Figure 2. AFM images (3D) as spin-coated (A) followed by corona-poled $(\mathrm{B})$ for a polymer film of 3 .

polyurethane. there was not resonant contribution to this $d_{33}$ value. In the isotropic model, the ratio of $d_{23} / d_{31}$ is predicted to be about 3 . Our $d_{32} / d_{31}$ value of 3.08 is in good agreenent with the predicted value. To evaluate the high-temperature stability of the polymers, we studied the temporal stability of the SHG signal. The poled polymer film of 3 exhibited no negligible decay of the $d_{3 z}$ signals up to $170^{\circ} \mathrm{C}$. These temporal thermal stabilities are probably due to the partial main chain character of polymer structure and hydrogen bonds between urethane linkage, which are acceptable for NLO device applications. We are now in the process of extending the polymerization system to the synthesis of other type of NLO polymers and the results will be reported elsewhere.

Acknowledgements. This work was supported by the Korea Researcl Foundation Grant (KRF-2002-04l-D00173).

\section{References}

1. Holecular Nonlinea Optics; Haterials, Phsics and Devices: Zyss. J.. Ed.; Academic Press: Orlando, FL, 1987: 1994.

2. Burland. D. M.: Miller. R. D.: Walsh, C. Chem Rev. 1994. 94, 31.

3. Han. K. S.: Park. S. K.; Shim. S. Y: Jahng. W. S.; Kim. N. J. Bull. Konan Chem. Soc. 1998. 19. 1165

4. Han. K. S.: Park. S. K.: Shim. S. Y.: Lee. Y. S.: Jahn1g. W. S.: Kinn. N. J. Bull. Konean Chent. Soc. 1998. 19.1168.

5. Lee. J.-H: Lee, K.-S. Bull. Kowam Chent. Soc. 2000. 21. 847.

6. Yu. D.: Gharavi, A.: Yu. L. Hacmomolecules 1996, 29.6139.

7. Kim. M. H.: Jin, J.-I.; Lee. C. J.; Kim, N. J: Park, K. H. Bull. Kowan Chem. Soc. 2002. 23.964.

8. Cullinatie. N. M. /. Chem. Soc. 1923. 123. 2053

9. Cistieros. T. I. Appl. Opt 1998. 37.5262.

10. Maker. P. D.; lerhune. R. W.: Nisenoti. M.: Savage, C. M. Ph Rev Lett. 1962, 8. 21.

11. Herman. W. N.: Havden, L. M. l. Opt. Soc. Am. B 1995, 12,416. 